\title{
A digital readiness check for the evaluation of supply chain aspects and company size for Industry $\mathbf{4 . 0}$
}

Markus Lassnig

Salzburg Research Forschungsgesellschaft mbH, Salzburg, Austria

Julian Marius Müller

University of Applied Sciences Kufstein Tyrol, Kufstein, Austria

Karin Klieber

Salzburg University, Salzburg, Austria, and

Alexander Zeisler and Max Schirl

Salzburg University of Applied Sciences, Puch bei Hallein, Austria

\begin{abstract}
Purpose - While there are several readiness assessments regarding digital transformation (DT) and Industry 4.0 in extant literature, this study aims to contribute to (a) a better understanding of digital readiness in supply chain (SC) aspects and (b) elaborate on differences between small and medium-sized enterprises (SMEs) and large enterprises.

Design/methodology/approach - The study is based on 409 companies that participated in the Digital Readiness Check (DRC) in the region of Salzburg (Austria) and Bavaria (Germany) - an online assessment for self-evaluating the digital readiness of companies.

Findings - The study's results provide insights for the categories of strategy, employees, initiation of business transactions and SC. These are further differentiated for SMEs and large enterprises.

Research limitations/implications - The study is limited to two regions in Austria and Germany, based on a self-evaluation of companies in a single point of time perspective. For future research, the results of this study should be expanded for different regions. Further, the results could be validated regarding external observations and measuring results at a later point of time.

Practical implications - The DRC may help companies in benchmarking themselves and gaining a better understanding about categories that must be improved, especially regarding SC aspects of DT.

Originality/value - The DRC extends extant literature regarding the differentiation between SMEs and large enterprises as well as focussing on SC aspects of DT.
\end{abstract}

Keywords Digital transformation, Industry 4.0, Industrial Internet of Things, Digitalization,

Digital readiness, SME

Paper type Research paper

\section{Introduction}

The term "Industry 4.0" refers to the fourth industrial revolution, based on cyber-physical systems and the Internet of things, which represent technological enablers of this digital industrial transformation (Kagermann et al., 2013). While digital transformation (DT) has several potentials, many companies struggle with its implementation (Ghobakhloo and Fathi, 2019). This difficulty is especially true for small and medium-sized enterprises (SMEs) that

(C) Markus Lassnig, Julian Marius Müller, Karin Klieber, Alexander Zeisler and Max Schirl. Published by Emerald Publishing Limited. This article is published under the Creative Commons Attribution (CC BY 4.0) license. Anyone may reproduce, distribute, translate and create derivative works of this article (for both commercial and non-commercial purposes), subject to full attribution to the original publication and authors. The full terms of this license may be seen at http://creativecommons.org/licences/by/4.0/ legalcode

This study has been partly financed by the programme "Interreg Austria-Bavaria 2014-2020".

Received 1 October 2020 Revised 27 January 2021 18 May 2021
A digital readiness Industry 4.0

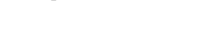


JMTM 33,9

often face limited digitalization level and resources. Moreover, SMEs encounter supply chain (SC) implementation problems, including competing interests, opportunism, transparency deficiencies and coordination requirements. These aspects are crucial for companies to approach their full potential, as integration across the SC is required (Ghadge et al., 2020; Veile et al., 2019, 2020). However, several challenges exist, especially the integration of SMEs into the SC (Horváth and Szabó, 2019; Mittal et al., 2018, 2020; Moeuf et al., 2020; Müller et al., 2018, 2020).

Several readiness assessments in extant literature relate to DT. These assessments do not focus on SC aspects of DT and do not consider the differentiation between SMEs and large enterprises. Nevertheless, both are vital for successful implementation. Against this background, the present study develops a DRC focussing on the SC aspects of DT and the differentiation between SMEs and large enterprises. The DRC presents empirical data from 409 companies in Salzburg (Austria) and Bavaria (Germany).

The sections of this study are organized as follows. Section 2 explains the relevant background on DT, Industry 4.0 and readiness checks in this context. Section 3 presents the method, including developing and collecting empirical data for the DRC. Section 4 discusses the results of the DRC and analyses company performance in DT with a particular focus on SMEs. After a discussion highlighting the contribution to the literature in Section 5, the paper presents the practical implications and limitations of the DRC and suggests future directions for self-assessment and benchmarking in Section 6.

\section{Literature review and research gap}

2.1 Digital readiness and maturity models

The digital readiness of companies may be defined as the capability to employ digitalization potential. Businesses may need to end ageing business models, invest in innovation or transform the core business altogether to achieve digital readiness. However, quantifying this process is a different matter, as varying degrees of digital readiness may be observed in practice. In context of DT, several readiness assessments and models have been developed, but not all of them have been empirically tested (Chonsawat and Sopadang, 2020; Mittal et al., 2018, 2020; Pirola et al., 2019; Sriram and Vinodh, 2020).

A widely accepted basis of maturity models is the capability maturity model proposed by Paulk et al. (1993). Originally developed to measure software maturity, this framework has since been adapted to many domains, including measuring maturity levels of digital readiness (De Carolis et al., 2017). Many other techniques to measure digital maturity exist. For example, Mittal et al. $(2018,2020)$ provided a concise overview and comparison of 16 different models. Although all previously mentioned models favour distinct approaches and domains, they all have one aspect in common: transforming the binary concept of digital readiness into a tiered model that differentiates various degrees of digital maturity or readiness.

\subsection{State of research and research gap}

The literature consensus is that SMEs are faced with the challenge to innovate different parts of their operations due to Industry 4.0 (Chen, 2020; Khanzode et al., 2020; Masood and Sonntag, 2020; Somohano-Rodríguez et al., 2020). To possess the required capabilities for innovation, SMEs require adequate resources, capabilities and strategies to innovate with limited resources and compound effects due to their small size (Cimini et al., 2020; Müller et al., 2018; Stentoft et al., 2020). Moreover, SMEs are often forced by their customer demands to innovate their processes and operations, requiring them to cooperate with suppliers and customers in the SC to make up for their lack of size. This situation reflects the importance of considering SC aspects and SMEs in Industry 4.0 research (Müller et al., 2018, 2020; Sahi et al., 
2020). However, as Müller et al. (2018) stated, the integration in the SMEs' SC has scarcely been considered in research in the context of Industry 4.0. For instance, Müller et al. (2021) find distinct characteristics of SMEs in comparison to large companies, being more operations-driven, that is, focussing on manufacturing innovations than on SC or customer integration. However, Müller et al. (2021) focussed on the perspective of business model innovation rather than SC aspects as such. While Ghobakhloo and Iranmanesh (2021) discuss several aspects of DT for SMEs, they do not present a direct comparison to large companies and do not consider SC aspects in detail.

Despite the importance of SC aspects and SMEs regarding Industry 4.0, a review of 20 maturity models for Industry 4.0 by Felch et al. (2019) revealed that only three out of 20 maturity models consider the aspect of SCs and only superficially do so. Wagire et al. (2020) provided an overview of 12 maturity models in the context of Industry 4.0. Digitalization from supplier to customer is only mentioned as a single factor. Two studies that more closely examine SCs and Industry 4.0 are by Samaranayake et al. (2017), but they still only address three items concerning SCs. A project from the University of Warwick investigated complex SCs but did not include the specific perspective of SMEs (WMG-University of Warwick, 2017).

Further, extant research has mainly focussed on maturity models for specific technologies or applications (Dutta et al., 2021; Mittal et al., 2018, 2020) or limited to specific cases of single companies (Amaral and Peças, 2021). The requirements of adequate financial resources, skills and strategy as an entry stage for Industry 4.0 can be found in other studies on Industry 4.0 and SMEs (Colli et al., 2018; Mittal et al., 2018, 2020; Müller et al., 2018; Schumacher et al., 2016; Wagire et al., 2020). However, most existing maturity models concerning Industry 4.0 draw a connection between technologies, strategy, culture and resources, as described in the review by Wagire et al. (2020). This paper complements this research by addressing the SC perspective and the differentiation between SMEs and large enterprises. Compared to research on maturity models regarding Industry 4.0, this research attempts to contribute to the missing perspective of supply chain management (SCM) focussing on SMEs. In summary, this paper aims to fill the following research gaps:

(1) SC aspects that have considerably been less investigated in maturity or readiness models in the context of Industry 4.0.

(2) SMEs' characteristics in comparison to large companies regarding digital readiness.

\section{Methodology}

\subsection{Project description and research design}

The DRC represents a project funded by the European Union in the German-Austrian border region between Bavaria and Salzburg. It assesses the development stage towards DT/ Industry 4.0 with a focus on SC aspects and a differentiation between SMEs and large enterprises. These three characteristics, (1) developing a readiness check, (2) extending the focus to the SC and (3) comparing SMEs and large enterprises, were clear targets, which were successfully approved by the funding agency. Therefore, a broader investigation, for example, across Austria, is intended by public agencies in the next years. Further, the DRC shall help companies to benchmark their own position and give them hints in which regards they might be lagging behind.

As a result of the assessment, especially SMEs are supported by scientific partners through a profound programme for knowledge transfer via different measures for awareness raising. These were explicitly demanded as a second step by the funding agency, for example, qualifying the personnel in workshops, excursions to laboratories for demonstration and the exchange of lessons learned between different enterprises.

A digital readiness check for Industry 4.0

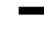


JMTM 33,9

\subsection{Questionnaire development}

The DRC aims to depict the attitudes of a participant regarding his or her perception of digitalization in the company she or he is employed with. In order to identify appropriate statements for the questionnaire, the design process was executed in three steps (Pham, 2010):

(1) Identify an appropriate reference model for SCM.

(2) Collect questions/statements from existing DRCs and maturity models.

(3) Make adjustments and add additional statements when required.

According to De Carolis et al. (2017), manufacturing key processes can be grouped into the following five processes: design and engineering, production management, quality management, maintenance management and logistics management. In addition to manufacturing processes, an appropriate strategy and the integration of employees are of core importance to manage digitalization successfully as well as the integration across the SC (Schmidt et al., 2020; Veile et al., 2019).

Therefore, the Supply Chain Operations Reference (SCOR) model was chosen, representing a widely spread reference model that describes processes, recommends key performance indicators to measure the performance and thus enables evaluating and comparing SC activities. The SCOR model has been developed to describe business activities associated with all phases of satisfying customer demand. It has a holistic character, being used in several scientific publications (APICS, 2017; Birkel and Müller, 2021; Huan et al., 2004). For the context of this project, the choice of SCOR was approved by the funding agency as the focus of the readiness check should be on the $\mathrm{SC}$ aspects accompanied by the respective internal factors.

The goals of processes in the phase "Enable" in the original SCOR model are to support the realization and governance of planning and execution processes of an SC. Thereby "Enable" processes interact with functions such as financial processes and human resources (APICS, 2017). As a clear differentiation of "Enable" processes between SCM and other functions is not always possible, it was decided to exclude "Enable" processes from the questionnaire. Instead, it was decided to include the initiation of business transactions. It reflects changing forms of cooperation and buyer-supplier relationships relating to Industry 4.0 that go beyond process-oriented aspects of the SCOR model (Ghadge et al., 2020; Schmidt et al., 2020; Veile et al., 2020).

Herewith, SCOR provided the underlying basis to structure the statements regarding digitalization of SCM, which represents the main focus of the DRC. The questionnaire and its items were complemented with a preceding and a closing block, and the structure was defined as follows:

(1) Strategy (Mittal et al., 2018, 2020; Müller et al., 2018; Schumacher et al., 2016).

(2) Employees (Mittal et al., 2018, 2020; Schumacher et al., 2016; Vereycken et al., 2021).

(3) Initiation of business transactions (Ghadge et al., 2020; Veile et al., 2020).

(4) Digitalization of the SC based on the SCOR model (APICS, 2017): Plan, Procurement (Source), Production (Make), Delivery and Return, Service and Maintenance.

(5) Data regarding company background.

Based on the above-named references, 24 items were defined that are displayed in the results section. For the definition of items, 17 DRCs and maturity models - such as Mittelstand 4.0 Competence Centre Kaiserslautern or IMPULS Foundation of the Mechanical Engineering Industry Assocation (VDMA) - were used as underlying basis. An overview can be found in 
Mittal et al. (2018) or Schuhmacher et al. (2016). In order to limit the length of the questionnaire, but also to enable a meaningful analysis of data, the authors decided to have three questions for each category.

The most common scale for measuring attitudes is the Likert scale, in which participants give their view on a set of statements (Diamantopoulos and Winklhofer, 2001). A selected set of statements was grouped into categories, and a consistent scale was elaborated for all questions in the respective DRC. The scale was set as a fixed end point scale, and the respondent can choose between six options - ranging from "strongly agree" to "strongly disagree". Thus, it is ensured that analysis methods - such as arithmetic mean or correlation analysis - can be applied properly. An even number of options reduces the risk that participants choose the middle category in case they cannot answer or do not have an opinion about a statement and thus falsify the result. An even number of options enforces the participant to choose one side of the answer (Diamantopoulos and Winklhofer, 2001). In case the participant cannot answer or has no opinion about a statement, a seventh option has been included ("n/a"), but this option was placed separately, outside of the scale.

A pre-test was performed in two phases. In phase 1, the focus was on content and understanding of the questions. This part of the pre-test was done paper-based, and 40 participants provided their feedback orally or in written form to the authors of this article. Participants of the pre-test were selected carefully within the network of the project team. All of them were in a relevant professional position, and all pre-tests were performed in the presence of a project member. In the second phase, the emphasis was placed on the technical implementation and usability.

\subsection{Data collection and analysis}

For data collection via the DRC, an online survey is used. In contrast to a traditional questionnaire, an online questionnaire achieves a higher response rate, and participants can easily stop and continue filling an online questionnaire. Further, online questionnaires are the main methods chosen in other readiness checks published.

The online questionnaire was promoted during workshops and further public events of the EU-funded project and via e-mail newsletter by public agencies supporting economic development. The participants stem from industrial enterprises across Bavaria (Germany) and Salzburg (Austria), two bordering regions with close economic links. Twenty-one questionnaires were removed from the sample as entries could be considered implausible since they exclusively contained extreme values across all questions. This led to a final sample of 409 companies that stated their status regarding digitalization in different business areas. According to the definition in the EU, companies employing "fewer than 250 persons and which have an annual turnover not exceeding EUR 50 million, and/or an annual balance sheet total not exceeding EUR 43 million" are considered as SMEs. In total, 237 SMEs and 65 large companies completed the online survey; 107 companies did not state their size and are therefore excluded from the evaluation of differences between SMEs and large companies below.

On the six-point Likert scale, companies are assumed to agree with a statement if they chose either "strongly agree" (6) or "agree" (5). Similarly, they are assumed to disagree with a statement if they chose "strongly disagree" (1) or "disagree" (2), as presented throughout the results section.

Data handling and analyses were performed with the statistics software R. It was used to calculate mean values, cumulated values for each of the answering options and ANOVA tests for mean comparisons. The results generated are illustrated in the next section. The figures show the cumulated values for each of the answering options, differentiated for strategy (section 4.1), employees (section 4.2), initiation of business transactions (section 4.3) and SC (section 4.4).
A digital readiness check for Industry 4.0 
JMTM 33,9

6

\section{Results}

\subsection{Strategy}

The first block of questions deals with general issues regarding a digitalization strategy and its implementation. Overall, the results show that companies commonly seem to commit a person or department for DT but miss out on a well-established process for its implementation. In total, $26 \%$ of the participants commit themselves to a digitalization strategy and even more - over $40 \%$ - already assigned a responsible person. However, only $21 \%$ state that they already pursue a well-established process for its implementation and advancement. All shares of given answers can be found in Figure 1.

Figure 2 shows the shares of given answers for both SMEs and large companies. Results show that SMEs and large companies adopted a digitalization strategy with targets and target values to a very similar extent. Both groups seem to have deficiencies in establishing a well-defined process for digital innovations. Interestingly, more than half of the large companies who responded to the questionnaire already assigned a person responsible for the topic "digitalization", whereas only about $40 \%$ of SMEs fill this position with a specific person.

\subsection{Employees}

Focussing on the perception of employees regarding digitalization, the next block of questions reveals details about the involvement of employees and the communication from managerial staff towards employees regarding the digitalization process. One-third of participating companies think that their employees are aware of chances and risks of digitalization. At the same time, however, the same share of companies admits that their employees are not very well prepared for the upcoming challenges. Nonetheless, $31 \%$ of companies think that the executive personnel perceptibly set examples regarding digitalization and the development of new competences, as presented in Figure 3 for the corresponding statement.

Figure 4 shows that SMEs are slightly ahead of large companies regarding the digitalization awareness and preparedness among employees. In total, 34\% of SMEs, compared to $27 \%$ of large companies, state that their employees are aware of the chances and

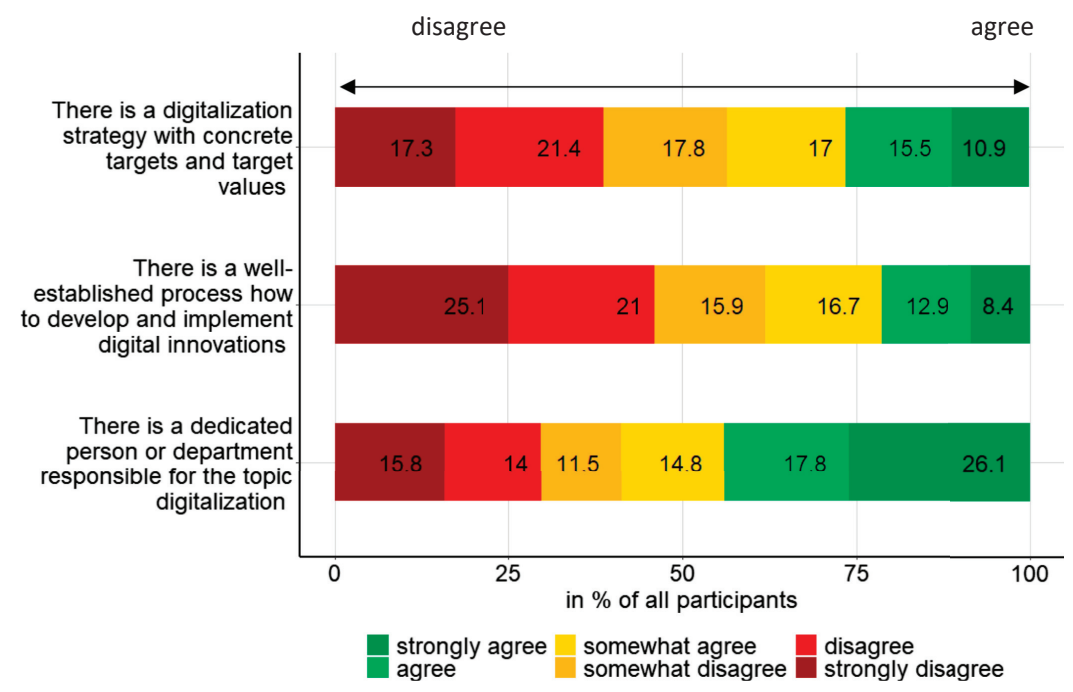

Note(s): Base: Responses from all companies, $N=409$
Figure 1.

Share of given answers in $\%$ in the area of strategy 


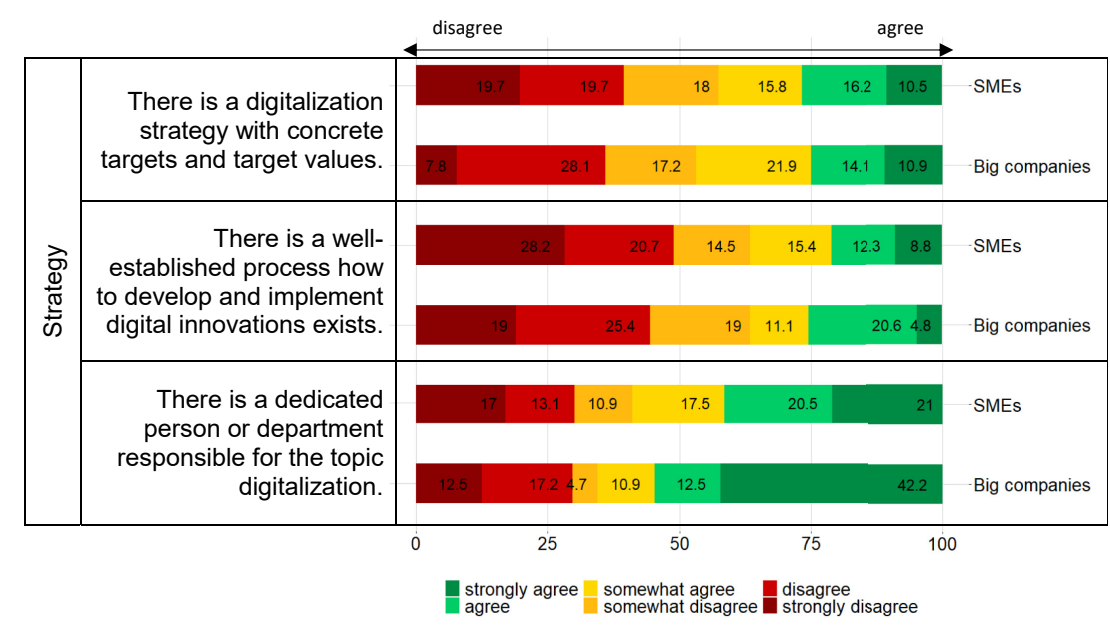

Note(s): Base: Responses from all companies indicating their size; $N=302$

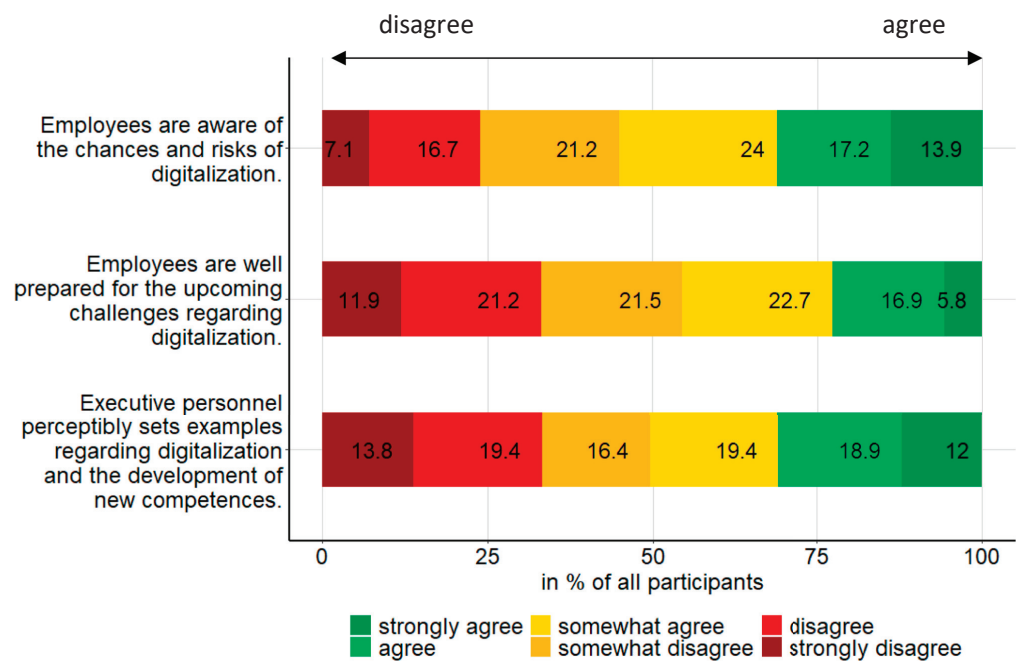

Note(s): Base: Responses from all companies, $N=409$

\section{A digital readiness check for Industry 4.0

Figure 2.

Comparison SMEs vs. large companies in the area of strategy
Figure 3.

Share of given answers in $\%$ in the area of employees

risks of digitalization. Similarly, 34\% of SMEs see their executive personnel setting examples regarding digitalization and development of new competences, whereas only $17 \%$ of large companies agreed with this statement.

\subsection{Initiation of business transactions}

Digitalization in the initiation of business transactions seems to be most advanced. Almost half of the participants declare that digital services complement traditional ways of customer acquisition and product advertising. Similarly, digital services support maintaining contacts 
JMTM 33,9

8

Figure 4.

Comparison SMEs vs. large companies in the area of employees
Figure 5.

Share of given answers in $\%$ in the area initiation of business transactions

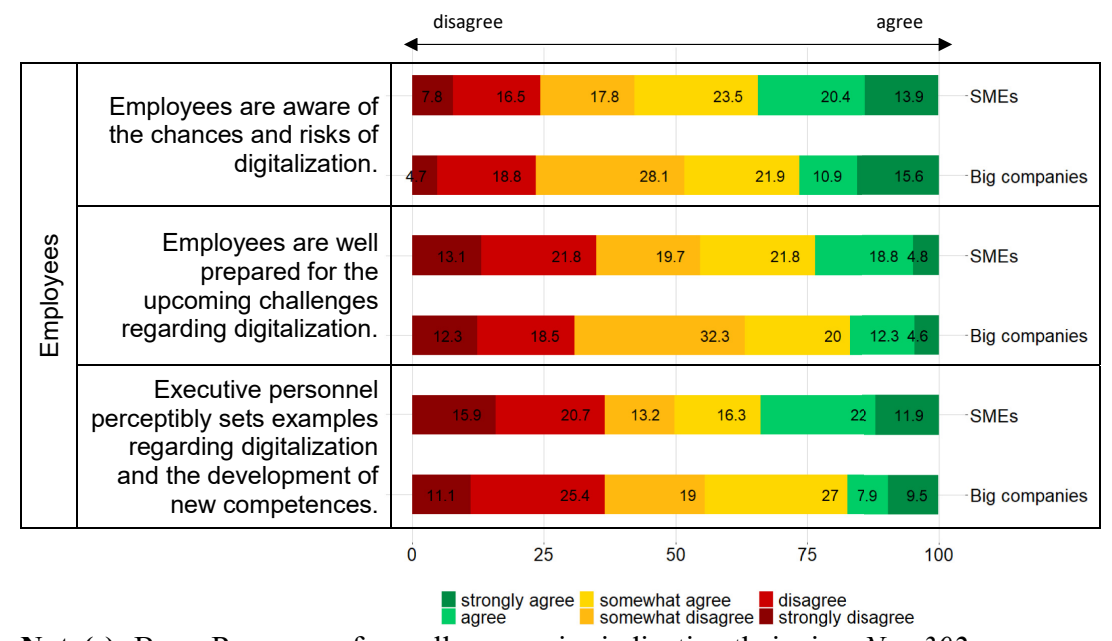

Note(s): Base: Responses from all companies indicating their size; $N=302$

with customers or prospective customers in $45 \%$ of the companies. Only the process of developing new products is not yet characterized by digital automation in most of the companies: In $44 \%$ of the companies, the process of product development is not accompanied by automated steps. Figure 5 provides details about the shares of given answers.

Regarding the initiation of business transactions, the differences between SMEs and large companies seem to be negligible. For all three questions, the shares of answers of SMEs and large companies distribute similarly across the six response options. This can be seen in Figure 6. Regardless of the company size, participants of the DRC state that digital services complement traditional ways of customer acquisition and product advertising to a large extent. In terms of maintaining contacts with customers, the process of digitalization is also

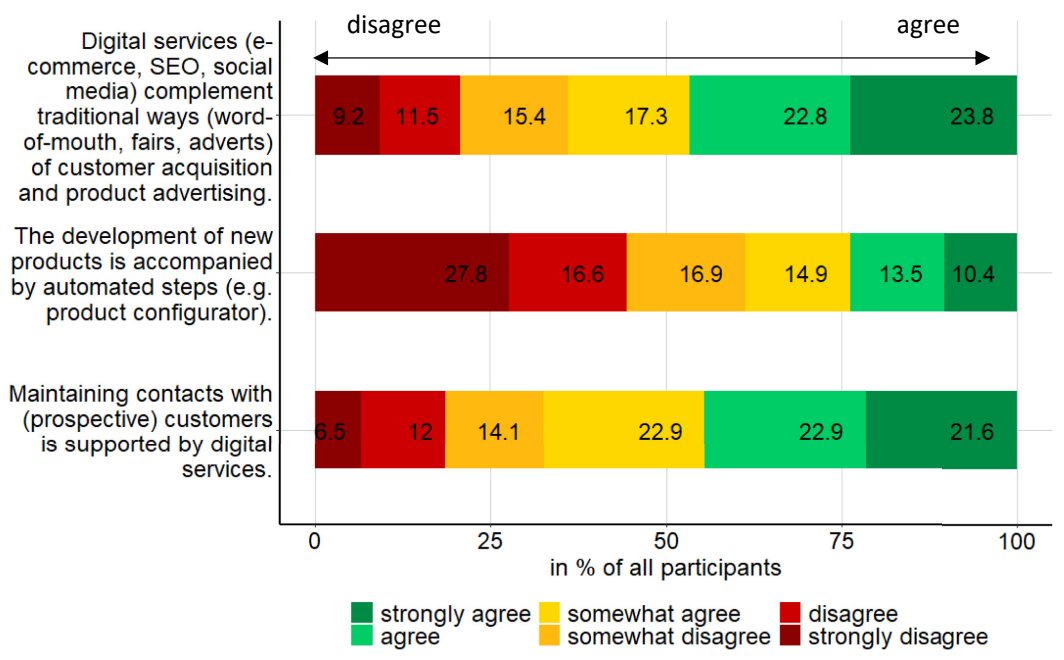

Note(s): Base: Responses from all companies, $N=409^{\circ}$ 


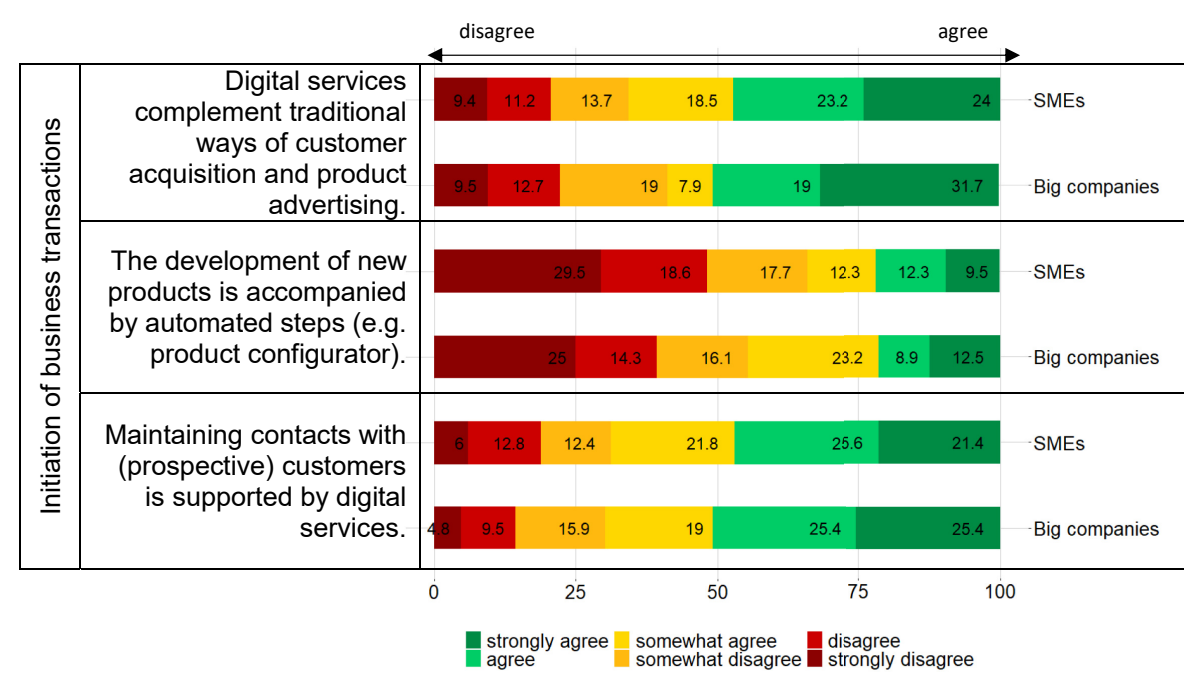

Note(s): Base: Responses from all companies indicating their size; $N=302$
A digital
readiness
check for
Industry 4.0

9

Figure 6.

Comparison SMEs vs. large companies in the area initiation of business transactions

quite advanced. In contrast, the development of new products does not seem to be accompanied by automated steps in many companies, neither in SMEs nor in large companies.

\subsection{Supply chain}

The study identifies the lowest degree of digitalization in the SC - compared to other business areas. In general, many companies share data and information already via digital platforms; however, automated processes and interconnected databased systems are rather rare.

One-fifth of the participating companies automated the planning of the production programme and introduced adaption and optimization with real-time data. Even more, 25\% exchange information between all divisions of the company digitally and autonomously. Similarly, data is shared with suppliers via a web-based platform in $29 \%$ of the companies. In contrast, only about $14 \%$ of participants automated their procurement of resources via sensor systems or share forecast data with their suppliers.

Regarding the production process, nearly $30 \%$ of core processes are digitalized to a great extent and the majority of production plants are digitally connected. However, more than half of the companies do not have systems that can react to changing conditions autonomously and in real time. The area of delivery shows a slightly more advanced stage of digitalization. More than $20 \%$ of the companies have IT systems, which automatically pool orders and perform billing and dunning. Web-based platforms support $27 \%$ of the companies in communicating with customers such as sharing or exchanging data and orders. Similarly, more than $20 \%$ offer a digital platform for communicating with customers regarding, for example, service and maintenance. However, the degree of automation is rather low, as more than half of the companies do not provide services regarding predictive and automated ordering or maintenance of products and spare parts. Details are given in Figure 7.

For a detailed comparison of SMEs and large companies, Figure 8 shows the shares of given answers by company size. The results show that SMEs and large companies give similar answers to most questions. For example, about $20 \%$ of SMEs and $25 \%$ of large companies already automated the planning of their production programme and $18 \%$ of SMEs 
JMTM

10
Figure 7.

Share of given answers in $\%$ in the areas of the SC

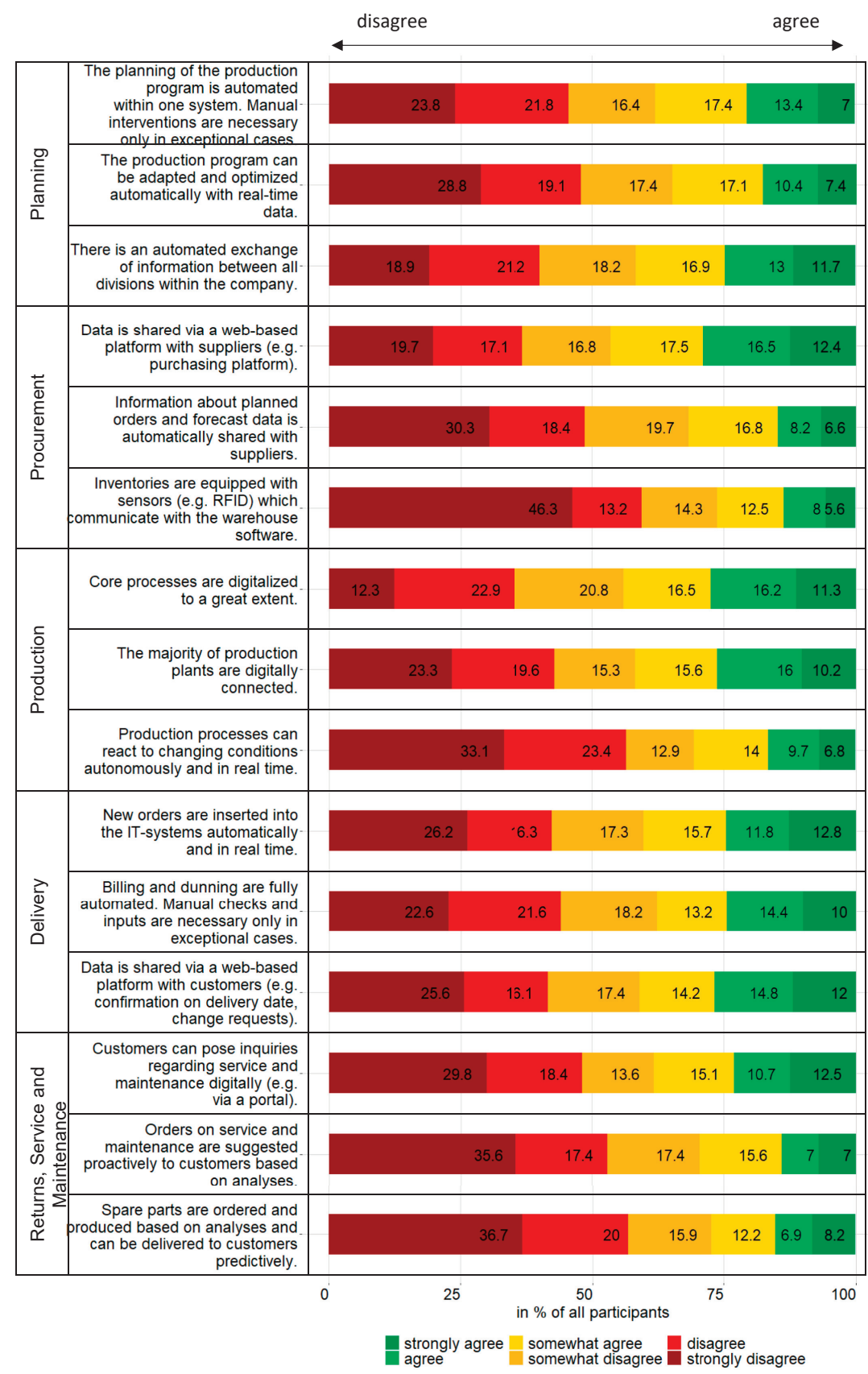

Note(s): Base: Responses from all companies, $N=409$ 


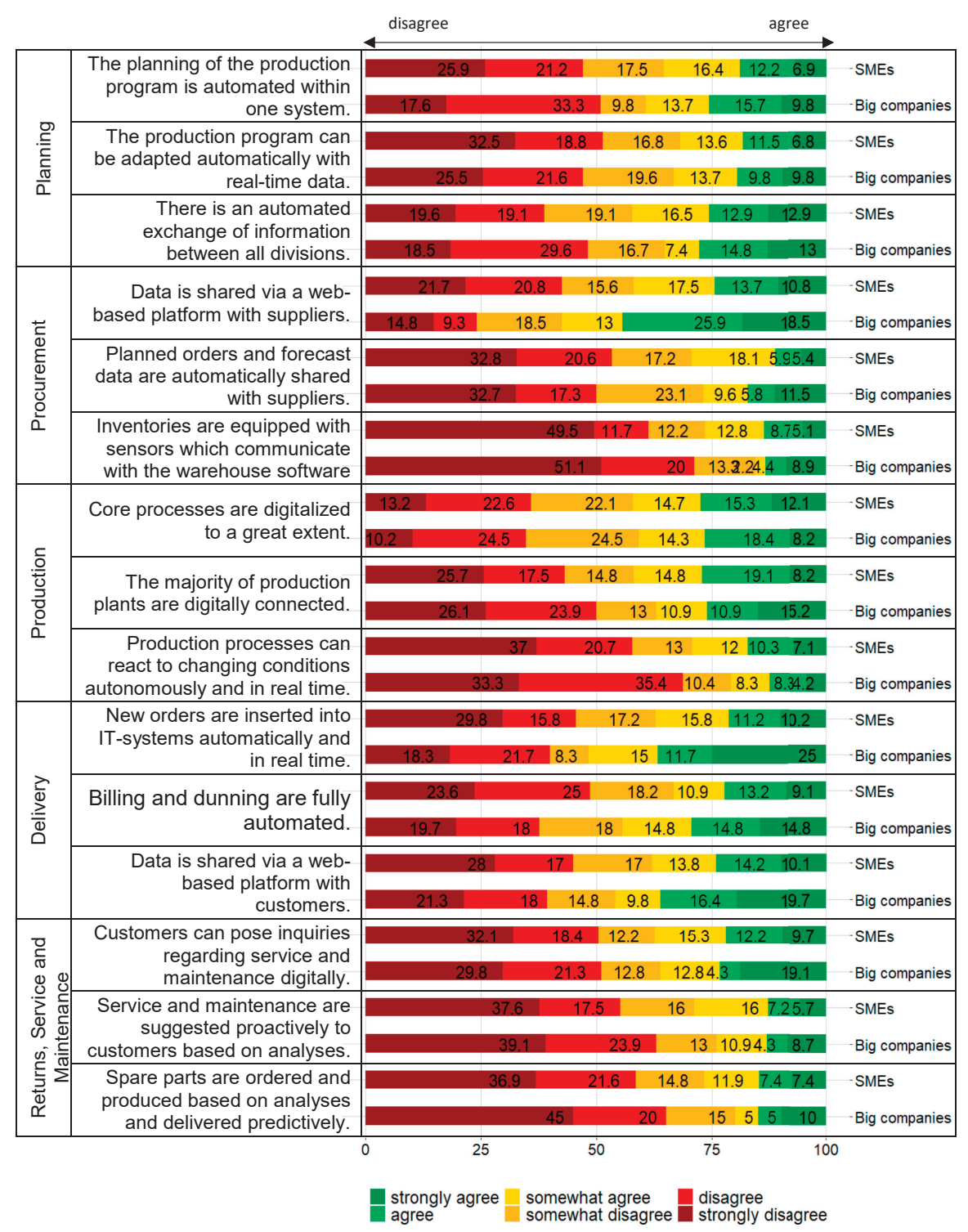

Note(s): Base: Responses from all companies indicating their size; $N=302$

\section{A digital readiness check for Industry 4.0}

11
Figure 8. Comparison SMEs vs. large companies in the areas of the $\mathrm{SC}$

and large companies regularly adapt their programme with real-time data. In total, $26 \%$ of SMEs and $28 \%$ of large companies implemented a system with automated exchange of information between departments. Sensor-based equipment and real-time data applications are still rare. This holds for SMEs as well as for large companies. Over $60 \%$ of SMEs and large companies state that they have not equipped their inventories with sensors and that their production processes cannot autonomously and in real time react to changing conditions. Moreover, more than $50 \%$ of SMEs and large companies do not automatically plan orders or 
JMTM 33,9

\section{2}

share forecast data with their suppliers. The same is true for databased services, which are hardly adopted in the companies. More than half of SMEs and large companies do not produce spare parts or suggest service or maintenance proactively based on data.

On the contrary, web-based applications seem to be already widely used in large companies but not in SMEs, revealing some striking differences by company size. In particular, $44 \%$ of large companies compared to only one-quarter of SMEs indicate that they use web-based platforms to share information with their suppliers. In total, $36 \%$ of large companies compared to $24 \%$ of SMEs share information with their customers via web-based platforms. Automated ordering occurs in $27 \%$ of large companies but only in $21 \%$ of SMEs.

Table 1 summarizes the results section, providing an overview of the strengths of SMEs and large companies, respectively.

The main differences between SMEs and large companies highlighted in Table 1 are evaluated in detail in section 5.1 and discussed with the results of extant literature.

\section{Discussion and theoretical implications}

\subsection{Characteristics of SMEs and large enterprises in digital transformation}

Several authors have claimed that SMEs and large companies could never compete on a level playing field (Horváth and Szabó, 2019; Mittal et al., 2018, 2020; Moeuf et al., 2020). In addition, the evaluation of self-assessments similar to the DRC developed by the VDMA in Germany concludes that large companies are a step ahead and are more likely to have a corporate strategy for digitalization (Lichtblau et al., 2015). More recently, Machado et al. (2019), in their "Industry 4.0 readiness online self-check", conducted interviews indicating that SMEs tend to lag behind.

In contrast, the findings of this study suggest that the strengths of SMEs and large enterprises in DT and Industry 4.0 are more nuanced. Especially regarding the employee

\begin{tabular}{|c|c|}
\hline & Strengths of SMEs and large companies \\
\hline (1) Strategy & $\begin{array}{l}\text { In large companies, there is typically a dedicated person or department } \\
\text { responsible for the topic digitalization in contrast to SMEs }\end{array}$ \\
\hline (2) Employees & In SMEs \\
\hline & $\begin{array}{l}\text { - Employees are more aware of the chances and risks of digitalization } \\
\text { - Employees are better prepared for the upcoming challenges regarding } \\
\text { digitalization } \\
\text { - Executive personnel set better examples regarding digitalization and the } \\
\text { development of new competences }\end{array}$ \\
\hline \multirow[t]{3}{*}{$\begin{array}{l}\text { (3) Initiation of business } \\
\text { transactions } \\
\text { (4) Supply chain }\end{array}$} & $\begin{array}{l}\text { Large companies are more developed in offering digital services that } \\
\text { complement traditional ways of customer acquisition and product advertising } \\
\text { In SMEs }\end{array}$ \\
\hline & $\begin{array}{l}\text { - Core processes are digitalized to a greater extent } \\
\text { - Production processes are more advanced in reacting to changing } \\
\text { conditions autonomously and in real time } \\
\text { In large companies }\end{array}$ \\
\hline & $\begin{array}{l}\text { - The planning of the production programme is rather automated within one } \\
\text { system } \\
\text { - Data is shared via a web-based platform with suppliers to a higher amount } \\
\text { - Planned orders and forecast data are shared with suppliers to a higher } \\
\text { amount } \\
\text { - Higher integration of orders into IT systems in real time } \\
\text { - Higher share of web-based platform usage with customers }\end{array}$ \\
\hline
\end{tabular}

Table 1.

Summary of comparison of SMEs' and large companies' strengths in digital transformation
In large companies, there is typically a dedicated person or department responsible for the topic digitalization in contrast to SMEs

- Employees are more aware of the chances and risks of digitalization Employees are better prepared for the upcoming challenges regarding

Executive personnel set better examples regarding digitalization and the pent new competences complement traditional ways of customer acquisition and product advertising

conditions autonomously and in real time

The planning of the production programme is rather automated within one Data is shared via a web-based platform with suppliers to a higher amount

Planned orders and forecast data are shared with suppliers to a higher

Higher integration of orders into IT systems in real time

Higher share of web-based platform usage with customers 
perspective and relating to core processes and production processes, SMEs are further advanced than their larger counterparts. Hence, this paper extends DRCs to SMEs and SC aspects, combining both perspectives. This research has scarcely been investigated in detail in readiness assessments, comparing SMEs and large enterprises (Chonsawat and Sopadang, 2020; Mittal et al., 2018, 2020; Pirola et al., 2019; Sriram and Vinodh, 2020; Wagire et al., 2020). The detailed differences between SMEs and large enterprises as found by this study are discussed in the following.

First, regarding strategy aspects, the results reveal that rather large companies have a dedicated person or department in charge of the strategy for Industry 4.0 and DT. In contrast, SMEs are typically flexible, with a chief executive officer or owner-driven management structure (Müller et al., 2018). Further, the results regarding the strategy for DT indicate that, although companies commonly commit themselves to a digitalization strategy, a clear and well-defined process for its implementation is often missing. The formulation of the strategy is the first inevitable step. For a successful implementation, a well-defined process must be communicated to all employees and partners. Several studies have emphasized the importance of all stakeholders along the value chain to undergo a successful digitalization process (Lichtblau et al., 2015; Machado et al., 2019). Especially for SMEs, collaboration with partners and stakeholders can reduce the lack of competencies and resources. Therefore, it is vital to understand strategic planning and operational implementation of DT, which is required to overcome several limitations and barriers to a successful transformation process, especially for SMEs with limited resources (Chen, 2020; Khanzode et al., 2020; Masood and Sonntag, 2020; Somohano-Rodríguez et al., 2020).

Second, referring to employees, respondents felt that employees are more aware of the opportunities and risks of digitalization and are better prepared for upcoming challenges and that executive personnel set examples regarding digitalization and developing new competencies (Vereycken et al., 2021). This result was unexpected following the previous studies (e.g. Horváth and Szabó, 2019; Moeuf et al., 2020; Müller et al., 2018). A possible explanation is that the strength of SMEs in DT might be the flexible, employee-oriented, family-like structure that better facilitates integrating employee requirements compared to large enterprises. Even if this assessment is based on self-evaluation, the perception that employees are integrated better in the DT process in SMEs reduces resistance and unlocks potential (Müller et al., 2018; Veile et al., 2019).

Third, the initiation of business transactions is one of the two areas where large companies are considerably ahead of SMEs, especially in terms of offering digital services that complement traditional ways of customer acquisition and product advertising. This complements to a rather product and production-oriented than service- or business modeldriven approach of SMEs towards Industry 4.0, as described below (Müller et al., 2021).

Fourth, regarding supply chain aspects, large companies are ahead in the automatic, realtime insertion of new orders in IT systems and sharing data with customers via a web-based platform, among other digital solutions for initiating business transactions, planning and data sharing. In this regard, SMEs need to catch up regarding data processing and exchange with customers. Generally, digitization of SC activities in SMEs seems less developed regarding Industry 4.0. This finding contributes to the literature, adding to the understanding that Industry 4.0 efforts of companies, especially SMEs, in their own enterprises are wellestablished, whereas SC aspects are neglected (Ghadge et al., 2020; Müller et al., 2021). As highlighted by this study, SMEs might not yet regard such approaches as supplier-relationship management or customer marketing as central processes (Veile et al., 2020).

Further relating to supply chain aspects, the study found that SME core processes are claimed to be highly automated within the sample, especially production processes. This claim indicates that SMEs are focussed on their core processes. This highlights the product orientation of many SMEs, whereas the service orientation or perspective on the business
A digital readiness check for Industry 4.0 
JMTM 33,9

model is less developed. In this way, we extend the findings of Müller et al. (2021) that showed that SMEs, regarding business model innovations, are focussing on product and production innovations while less considering SC and customer integration. This might be as SMEs do not see $\mathrm{SC}$ processes as relevant or complex enough to introduce digitized solutions, whereas production and products are seen as the core of their business. However, addressing customer or supplier-related digitization approaches offers many benefits for SMEs in order to offer new business models by offering new services and taking new roles as service providers in the supply chain, for example, for data analytics (Müller et al., 2021).

In sum, although many studies have suggested that SMEs primarily struggle with digital deficits, the results do not confirm this assessment. Instead, the results complement this suggestion with nuanced aspects differentiating between large companies and SMEs regarding their readiness for Industry 4.0. In general, a positive trend exists regarding the digitalization of processes and systems in SMEs and large companies.

Recently, SMEs are catching up, indicating a higher level of digitalization compared to previous studies (Cimini et al., 2020; Stentoft et al., 2020). This finding is supported by the DRC results, revealing that SMEs and large companies are aware of the DT and are implementing their strategies to the same extent. Further, SMEs are leading in terms of integrating employees and digitizing core and production processes. Nevertheless, the study reveals that the overall level of automation and data-based analysis is relatively low, especially across the SC. Hence, implementing these technologies remains an important task, as described in section 6.1 on managerial implications.

\subsection{Theoretical contribution}

In comparison to extant research on maturity models towards Industry 4.0, this research makes several contributions and extensions to the existing literature. The preconditions of having adequate financial resources, skills and strategy as an entering stage towards Industry 4.0 can generally be found in other studies (Colli et al., 2018; Mittal et al., 2018; Schumacher et al., 2016; Wagire et al., 2020). But whereas most existing maturity models towards Industry 4.0 draw a connection between technologies, strategy, culture and resources (Wagire et al., 2020), this paper extends this view by integrating and SC processes. Hereby, the findings highlight differences between production and logistics processes, whereas SMEs seem to focus on the former regarding DT and Industry 4.0 in contrast to large enterprises. Especially for SMEs, this highlights the requirement to better engage with their SC partners regarding DT and Industry 4.0 (Schmidt et al., 2020; Veile et al., 2019).

In sum, this paper extends the focus of extant research on maturity models for specific technologies or applications (Dutta et al., 2021; Mittal et al., 2018, 2020) or limited to specific cases of single companies (Amaral and Peças, 2021). Instead, it presents results of a broad sample of SMEs and large enterprises and compares both groups regarding specific strengths and characteristics. It further contributes to the missing SC perspective of extant maturity or readiness models that also consider SMEs, in which company-external perspectives are only marginally evaluated (Felch et al., 2019; Wagire et al., 2020). By presenting both internal and external perspectives on maturity towards DT and Industry 4.0, a combined perspective is generated that allows to compare SMEs and large enterprises regarding specific characteristics, as presented in Table 1.

The finding that SMEs are focussing on operational and core processes, such as production processes, extends the findings of Müller et al. (2021) regarding an exploitation and optimization focus of SMEs rather than exploring new business models. In particular, the paper finds that it not only tend to focus on operational processes, but specifically on production-related processes rather than with their customers and suppliers. Hence, future research should better understand and differentiate between SMEs' company-internal (Dutta et al., 2021) and company-external digitization approaches. 
The higher perception of respondents from SMEs towards readiness regarding strategy and leadership must further be better understood (Vereycken et al., 2021). While several authors emphasize the importance of adequate digitization strategies in SMEs (e.g. Colli et al., 2018; Mittal et al., 2018, 2020 Schumacher et al., 2016), an even higher perception in SMEs must be further evaluated and understood if this is an evaluation of perception or causality. In any case, the more flexible structure, allowing faster transformation processes of SMEs could be an explanation in this regard in which SMEs have waited for a long time regarding DT and Industry 4.0, but are now beginning to catch up (Müller et al., 2018).

\section{Conclusion}

\subsection{Managerial implications}

Based on raising awareness for digitalization and automation in all business activity areas among SMEs, the DRC acts as a self-evaluation assessment and provides information about the digitization level. An additional benefit not addressed in this paper was realized in the online assessment, which compares a participating company's answers with the mean of all given answers at the end of the online survey. Thus, the DRC provides ad hoc insight into the performance and progress of digitalizing core processes in the form of a benchmark. The online assessment further draws attention to the advantages of digital and data-based activities, especially across the $\mathrm{SC}$, promoting the acceleration of these pursuits.

The DRC compares companies in a broad field of activities and areas. The check promotes ideas regarding company processes and activities that could benefit from digitalization or ideas that already enjoy a high degree of automation in other companies. These insights are even more valuable for participating companies because they provide benchmarks between similar companies from the same region. Respective comparisons with companies of a similar size in the same region are better for raising awareness of the necessity of digitalization and providing respective guidance than a random comparison with very different companies from farther away. The DRC is designed to illustrate the digitalization level, pointing out potential deficits while offering an inspiring and advisory effect.

As a general recommendation based on the results, strategy, accountability and planning of DT processes are vital and comparably well established in SMEs and large firms. Additionally, while core processes, such as production, might be increasingly digitized in SMEs, the digitization and integration of SC processes with customers and suppliers must not be neglected for all enterprises. SC aspects of Industry 4.0 implementation are generally lagging and must draw greater attention from companies, especially for platform-based technologies, data sharing and autonomous processes across the SC. While the concept of Industry 4.0 draws on integration across the entire SC to unfold its full potential (Kagermann et al., 2013; Veile et al., 2020), it is still often considered and implemented only within the company borders.

Nevertheless, the overall positive finding for SMEs may not be misinterpreted as indicating SMEs are no longer in danger of missing out on DT. Many laggards are in danger of losing ground if they do not enforce their activities for digitalization. These companies (both SMEs and large enterprises) might not have participated in this survey.

\subsection{Limitations and future research}

Due to the nature of the DRC as an online survey designed to be completed unsupervised, several biases may have influenced the sample. Trying to reduce possible sampling bias has proved difficult because the DRC was primarily promoted at different events and via newsletters by email targeted at enterprises in Bavaria and Salzburg. Reaching company representatives who are generally unaware of rapid digitalization developments or who are already lagging also proved difficult. Further, a study including self-evaluation naturally 
JMTM 33,9

produces limited results due to the self-reporting bias. Hence, the results of this study can report the perception of respondents towards the respective topics, while the actual situation at their companies was not measured directly, but only indirectly via the respondents' opinion. This becomes especially relevant when considering aspects such as employees' awareness or perception of strategies towards DT or Industry 4.0.

Further, the study is limited to the company self-evaluation in two regions in Austria and Germany at a single time point. For future research, the study results should be expanded to different regions. Furthermore, the results can be extended to external observations and measuring results to investigate developments over time.

To improve these limitations, a revised version of the $\mathrm{DRC}$ is already in development. It will be used in other projects focussing on digitalization and will be the main factor in raising awareness of the importance of digitalization in SMEs. In future work, revisiting the survey results collected between January 2019 and August 2020 may lead to further insight into the development of digital maturity in local businesses in Salzburg and Bavaria.

For future studies, this paper suggests investigating the relationship between organizational structure, employee inclusion and DT performance in detail, as highlighted by the results. A second general recommendation is to analyse SC aspects and their interrelatedness with the DT of internal processes in more detail. Third, the cooperation between SMEs and large enterprises regarding these aspects represents a productive research avenue.

\section{References}

Amaral, A. and Peças, P. (2021), "SMEs and Industry 4.0: two case studies of digitalization for a smoother integration", Computers in Industry, Vol. 125, 103333.

APICS (2017), "Supply chain operations reference model, version 12.0", available at: https:/apics.org/ scor (accessed 4 June 2020).

Birkel, H.S. and Müller, J.M. (2021), "Potentials of industry 4.0 for supply chain management within the triple bottom line of sustainability - a systematic literature review", Journal of Cleaner Production, 125612.

Chen, C.L. (2020), "Cross-disciplinary innovations by Taiwanese manufacturing SMEs in the context of Industry 4.0", Journal of Manufacturing Technology Management, Vol. 31 No. 6, pp. 1145-1168.

Chonsawat, N. and Sopadang, A. (2020), "Defining SMEs' 4.0 readiness indicators", Applied Sciences, Vol. 10 No. 24, p. 8998.

Cimini, C., Boffelli, A., Lagorio, A., Kalchschmidt, M. and Pinto, R. (2020), "How do industry 4.0 technologies influence organisational change? An empirical analysis of Italian SMEs", Journal of Manufacturing Technology Management, Vol. 32 No. 3, pp. 695-721.

Colli, M., Madsen, O., Berger, U., Møller, C., Wæhrens, B.V. and Bockholt, M. (2018), "Contextualizing the outcome of a maturity assessment for Industry 4.0", IFAC-PapersOnline, Vol. 51 No. 11, pp. 1347-1352.

De Carolis, A., Macchi, M., Negri, E. and Terzi, S. (2017), "A maturity model for assessing the digital readiness of manufacturing companies", IFIP International Conference on Advances in Production Management Systems, Springer, Cham, pp. 13-20.

Diamantopoulos, A. and Winklhofer, H.M. (2001), "Index construction with formative indicators: an alternative to scale development”, Journal of Marketing Research, Vol. 38 No. 2, pp. 269-277.

Dutta, G., Kumar, R., Sindhwani, R. and Singh, R.K. (2021), "Digitalization priorities of quality control processes for SMEs: a conceptual study in perspective of Industry 4.0 adoption", Journal of Intelligent Manufacturing, Vol. 32, pp. 1679-1698.

Felch, V., Asdecker, B. and Sucky, E. (2019), "Maturity models in the age of Industry 4.0 - do the available models correspond to the needs of business practice?", Proceedings of the 52nd Hawaii International Conference on System Sciences, 2019. 
Ghadge, A., Kara, M.E., Moradlou, H. and Goswami, M. (2020), "The impact of Industry 4.0 implementation on supply chains", Journal of Manufacturing Technology Management, Vol. 31 No. 4, pp. 669-686.

Ghobakhloo, M. and Fathi, M. (2019), "Corporate survival in Industry 4.0 era: the enabling role of leandigitized manufacturing”, Journal of Manufacturing Technology Management, Vol. 31 No. 1, pp. 1-30.

Ghobakhloo, M. and Iranmanesh, M. (2021), "Digital transformation success under Industry 4.0: a strategic guideline for manufacturing SMEs", Journal of Manufacturing Technology Management, Vol. 32 No. 8, pp. 1533-1556.

Horváth, D. and Szabó, R.Z. (2019), "Driving forces and barriers of Industry 4.0: do multinational and small and medium-sized companies have equal opportunities?", Technological Forecasting and Social Change, Vol. 146, pp. 119-132.

Huan, S.H., Sheoran, S.K. and Wang, G. (2004), "A review and analysis of Supply Chain operations reference (SCOR) model”, Supply Chain Management: An International Journal, Vol. 9 No. 1, pp. 23-29.

IMPULS Foundation of the German Mechanical Engineering Industry Assocation (2020), "Industrie 4.0-Readiness Online-Selbst-Check für Unternehmen", available at: https://www.industrie40readiness.de/index.php (accessed 18 September 2020).

Kagermann, H., Wahlster, W. and Helbig, J. (2013), "Recommendations for implementing the strategic initiative Industrie 4.0: final report of the Industrie 4.0 working group", Communication Promoters Group of the Industry-Science Research Alliance, Acatech, Frankfurt am Main.

Khanzode, A.G., Sarma, P.R., Mangla, S.K. and Yuan, H. (2020), "Modeling the industry 4.0 adoption for sustainable production in micro, small and medium enterprises", Journal of Cleaner Production, 123489.

Lichtblau, K., Stich, V., Bertenrath, R., Blum, M., Bleider, M., Millack, A., Schmitt, K., Schmitz, E. and Schröter, M. (2015), "Industrie 4.0-readiness", Aachen Köln, available at: https://industrie40. vdma.org/documents/4214230/26342484/Industrie_40_Readiness_Study_1529498007918.pdf (accessed 14 January 2021).

Machado, C.G., Winroth, M., Carlsson, D., Almström, P., Centerholt, V. and Hallin, M. (2019), "Industry 4.0 readiness in manufacturing companies: challenges and enablers towards increased digitalization”, Procedia CIRP, Vol. 81, pp. 1113-1118.

Masood, T. and Sonntag, P. (2020), "Industry 4.0: adoption challenges and benefits for SMEs", Computers in Industry, Vol. 121, 103261.

Mittal, S., Khan, M.A., Romero, D. and Wuest, T. (2018), "A critical review of smart manufacturing and Industry 4.0 maturity models: implications for small and medium-sized enterprises (SMEs)", Journal of Manufacturing Systems, Vol. 49, pp. 194-214.

Mittal, S., Khan, M.A., Purohit, J.K., Menon, K., Romero, D. and Wuest, T. (2020), "A smart manufacturing adoption framework for SMEs", International Journal of Production Research, Vol. 58 No. 5, pp. 1555-1573.

Moeuf, A., Lamouri, S., Pellerin, R., Tamayo-Giraldo, S., Tobon-Valencia, E. and Eburdy, R. (2020), "Identification of critical success factors, risks and opportunities of Industry 4.0 in SMEs", International Journal of Production Research, Vol. 58 No. 5, pp. 1384-1400.

Müller, J., Buliga, O. and Voigt, K.-I. (2018), "Fortune favors the prepared: how SMEs approach business model innovations in Industry 4.0", Technological Forecasting and Social Change, Vol. 132, pp. 2-17.

Müller, J.M., Veile, J.W. and Voigt, K.-I. (2020), "Prerequisites and incentives for digital information sharing in Industry 4.0 - an international comparison across data types", Computers and Industrial Engineering, Vol. 148, p. 106733.

Müller, J.M., Buliga, O. and Voigt, K.I. (2021), "The role of absorptive capacity and innovation strategy in the design of industry 4.0 business Models - a comparison between SMEs and large enterprises”, European Management Journal, Vol. 39 No. 3, pp. 333-343.

A digital readiness check for Industry 4.0 
JMTM 33,9
Paulk, M.C., Curtis, B., Chrissis, M.B. and Weber, C.V. (1993), "Capability maturity model, version 1.1", IEEE Software, Vol. 10 No. 4, pp. 18-27, 1 October 2020.

Pham, Q.T. (2010), "Measuring the ICT maturity of SMEs", Journal of Knowledge Management Practice, Vol. 11 No. 1, pp. 1-14.

Pirola, F., Cimini, C. and Pinto, R. (2019), "Digital readiness assessment of Italian SMEs: a case-study research”, Journal of Manufacturing Technology Management, Vol. 31 No. 5, pp. 1045-1083.

Sahi, G.K., Gupta, M.C. and Cheng, T.C.E. (2020), "The effects of strategic orientation on operational ambidexterity: a study of Indian SMEs in the industry 4.0 era", International Journal of Production Economics, Vol. 220.

Samaranayake, P., Ramanathan, K. and Laosirihongthong, T. (2017), "Implementing industry 4.0: a technological readiness perspective", IEEE International Conference on Industrial Engineering and Engineering Management, Singapore, 10-13 December.

Schmidt, M.C., Veile, J.W., Müller, J.M. and Voigt, K.I. (2020), "Ecosystems 4.0: redesigning global value chains", International Journal of Logistics Management, Vol. 32 No. 4, pp. 1124-1149, doi: 10.1108/IJLM-03-2020-0145.

Schumacher, A., Erol, S. and Sihn, W. (2016), “A maturity model for assessing Industry 4.0 readiness and maturity of manufacturing enterprises", Procedia CIRP, Vol. 52 No. 1, pp. 161-166.

Somohano-Rodríguez, F.M., Madrid-Guijarro, A. and López-Fernández, J.M. (2020), "Does Industry 4.0 really matter for SME innovation?", Journal of Small Business Management, Vol. ahead of print No. ahead of print.

Sriram, R.M. and Vinodh, S. (2020), "Analysis of readiness factors for Industry 4.0 implementation in SMEs using COPRAS”, International Journal of Quality and Reliability Management, Vol. 38 No. 5, pp. 1178-1192.

Stentoft, J., Adsbøll Wickstrøm, K., Philipsen, K. and Haug, A. (2020), "Drivers and barriers for Industry 4.0 readiness and practice: empirical evidence from small and medium-sized manufacturers", Production Planning and Control, Vol. 32 No. 10, pp. 811-828.

Veile, J.W., Kiel, D., Müller, J.M. and Voigt, K.-I. (2019), "Lessons learned from Industry 4.0 implementation in the German manufacturing industry", Journal of Manufacturing Technology Management, Vol. 31 No. 5, pp. 977-997.

Veile, J.W., Schmidt, M.C., Müller, J.M. and Voigt, K.-I. (2020), "Relationship follows technology! How Industry 4.0 reshapes future buyer-supplier relationships", Journal of Manufacturing Technology Management, Vol. 32 No. 6, pp. 1245-1266.

Vereycken, Y., Ramioul, M., Desiere, S. and Bal, M. (2021), "Human resource practices accompanying industry 4.0 in European manufacturing industry", Journal of Manufacturing Technology Management, Vol. 32 No. 5, pp. 1016-1036.

Wagire, A.A., Joshi, R., Rathore, A.P.S. and Jain, R. (2020), "Development of maturity model for assessing the implementation of Industry 4.0: learning from theory and practice", Production Planning and Control, in press.

WMG - University of Warwick (2017), “An industry 4 readiness assessment tool”, available at: https:// warwick.ac.uk/fac/sci/wmg/research/scip/reports/final_version_of_i4_report_for_use_on_ websites.pdf (accessed 11 January 2021).

\section{Corresponding author}

Markus Lassnig can be contacted at: markus.lassnig@salzburgresearch.at

For instructions on how to order reprints of this article, please visit our website:

www.emeraldgrouppublishing.com/licensing/reprints.htm

Or contact us for further details: permissions@emeraldinsight.com 